\title{
GEOPOTENTIAL MODELS AS A TOOL OF DENSIFYING GRAVITY FOR ORTHOMETRIC CORRECTION COMPUTATION
}

\author{
Dr. Raaed Mohamed Kamel Hassouna \\ Department of Civil Engineering, Faculty of Engineering in Shebin El-Kom, \\ Minoufiya University, Shebin El-Kom, Egypt
}

\begin{abstract}
:
In the current study, the global geopotential harmonic models are used to densify gravity values along precise leveling routes, and hence to minimize the discretization error in computing the orthometric correction and to represent an economical alternative. Furthermore, these models are checked regarding their capability of being the only source of gravity information along spirit leveling lines. The orthometric corrections, computed for two simulated test links, are compared with those resulting from using purely observed gravity. Based on the obtained results, it is recommended to use the geopotential harmonic models as an economical source of gravity information along precise levelling routes. Moreover, it is recommended to investigate the application of the remove-restore technique of geopotential models in the computation of orthometric correction.
\end{abstract}

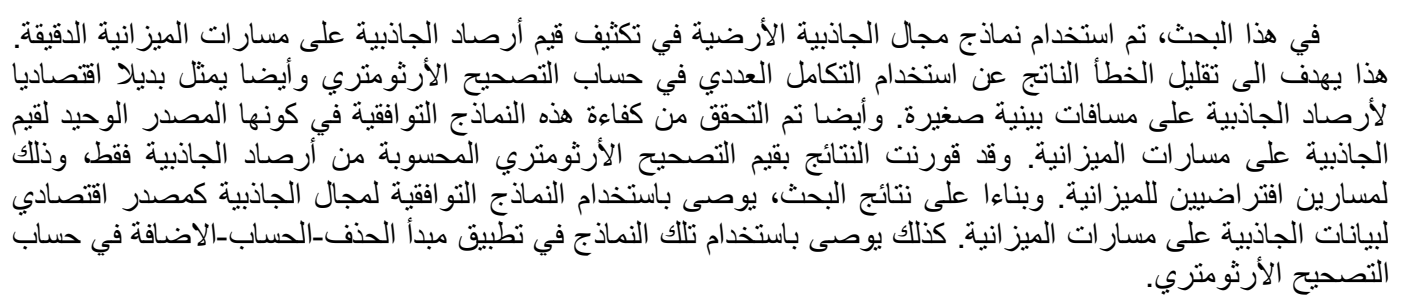

KEYWORDS: Orthometric correction - Geopotential models - Spirit leveling.

\section{INTRODUCTION}

Among the Gravity field related height systems, the orthometric height is the well accepted one, since it has both a geometric and natural meaning [7]. The orthometric height $(\mathrm{OH})$ can be obtained by spirit leveling. However, height differences from leveling must be corrected for the non-parallel equipotential surfaces using the orthometric correction $(O C)$ in order to obtain $\mathrm{OHs}$ [3], [4].

The evaluation of the precision of a gravimetric geoid model can be performed by comparing the relevant values with the geoidal heights computed from the difference between GPS-determined ellipsoidal heights and the $\mathrm{OHs}$ obtained from leveling. Recent progress in both theory and numerical technique has greatly improved the precision of geoid modeling. However, inaccurate orthometric heights will make such geoid model evaluation unreliable [5].

Recently, the computation of $\mathrm{OH}$ has been revisited by many researchers. The aim of such works was the development of rigorous computational methods for assessing the orthometric correction, e.g., [1], [5], [12] and [13]. These studies concentrated on the topographic and/or density effect on the $O C$. Such trend was also motivated by the fact that a so computed $\mathrm{OH}$ would be consistent with a gravimetric geoid that already possesses a terrain correction.

Rigorous $O C$ computation is expensive because it requires observed gravity values at benchmarks along the leveling route [2], [8]. Different methods for assessing $O C$ may yield different $O H s$ and the differences can reach several centimeters. This implies that $\mathrm{OHs}$ from leveling may mismatch the true orthometric heights by several centi-meters if the $O C$ computation is not sufficiently accurate [5].

Motivated from above facts, one could suppose that gravity observations along leveling routes approximately have not accurate long-wavelength components that could be evaluated by geopotenial harmonic models. Such low frequency features could constitute the major trends of level surfaces. Therefore, the aim of the current study is to investigate the ability of using global geopotential models to densify gravity acceleration along leveling 
lines, thus minimizing the discretization error in the computation of $O C$ and saving the cost of gravity measurements. Moreover, such models will be tested against their capability to be the only source of gravity along the leveling lines. Such investigations will be compared with the results of using purely observed gravity data and with an approximate method for computing the $O C$. The investigations encountering observed and harmonic models-derived gravity will be executed using two rigorous formulae [4], [5]. Alternatively, an approximate formula [8], which leans on normal gravity only, will also be tried.

\section{BASIC CONCEPTS}

The $\mathrm{OH}$ is the height, $\mathrm{H}$, above the geoid measured along the curved plumb line. Leveling alone will yield a geometric height difference between two consecutive benchmarks, which in turn yields $O H$ differences that are dependent on the leveling route. Thus, the $O C$ plays a critical role in obtaining unique $\mathrm{OH}$ s from leveling. By definition, the $\mathrm{OH}$ at a benchmark is the ratio between its geopotential number and the mean gravity along the plumb line $(\hat{\mathrm{g}})$ between the relevant geopotential surface and the geoid. Thus, for two benchmarks A and B [4] (see Figure (1) )

$$
\begin{aligned}
O C_{A B}= & {\left[\sum_{i=1}^{k}\left[\left(g_{i}-\gamma_{0}\right) / \gamma_{0}\right] . \delta n_{i}\right]+\left[\left(\hat{g}_{A}-\gamma_{0}\right) / \gamma_{0}\right] H_{A} } \\
& -\left[\left(\hat{g}_{B}-\gamma_{0}\right) / \gamma_{0}\right] H_{B},
\end{aligned}
$$

where

$\delta n_{i} \quad:$ is the measured height increment at the $\mathrm{i}^{\text {th }}$ leveling section,

$k \quad:$ the total number of leveling sections,

$g_{i} \quad:$ the observed gravity relevant to the $\mathrm{i}^{\text {th }}$ section,

$\gamma_{0}:$ : the normal gravity at geodetic latitude $45^{\circ}$

on the reference ellipsoid (taken WGS-84),

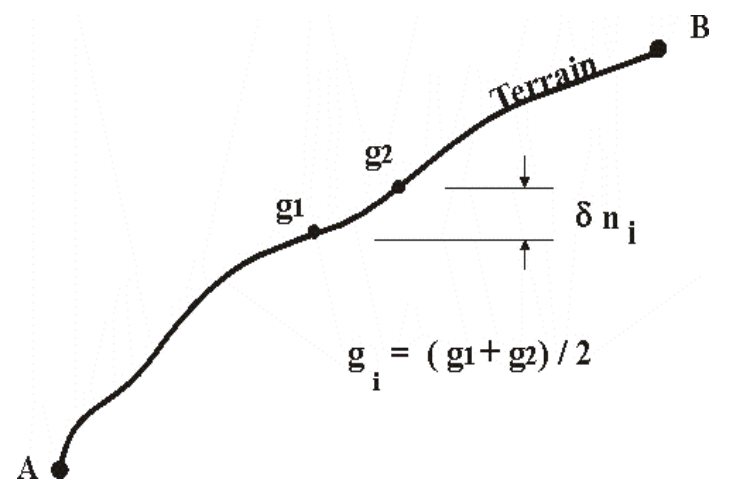

Figure (1): Surface gravity at the $i^{\text {th }}$ leveling section
$H_{A} \& H_{B} \quad:$ the orthometric height of $\mathrm{A}$ and $\mathrm{B}$, which heights, can be approximated by their leveled

$\hat{g}_{A} \& \hat{g}_{B} \quad$ : the mean gravity values along the plumb line at $\mathrm{A}$ and $\mathrm{B}$, respectively.

Assuming a constant topographic mass density of $2.67 \mathrm{gm} / \mathrm{cm}^{3}$, then according to Prey's reduction, one obtains [7]

$\hat{g}_{A}=g_{A}+0.0424 H_{A}$,

$\hat{g}_{B}=g_{B}+0.0424 H_{B}$,

(2)

where $g_{A}$ and $g_{B}$ are the observed gravity (in mgal) at $\mathrm{A}$ and $\mathrm{B}$, respectively. It should be mentioned that any leveling section simply consists of selected accumulated leveling setups, since it would be very impractical to measure gravity at each level setup [1], [2] and [8].

The magnitude of the $O C$ can be thought of as a measure of the convergence of equipotential surfaces [1]. It is clear that the dominant factors that judge the $O C^{\prime}$ 's magnitude are the spirit-leveled height differences $\left(\delta n_{i}\right)$, the deviation of observed gravity from normal gravity and the average elevation of the leveling link. Recently, a new formula for assessing $O C$ has been derived by [5], namely,

$O C_{A B}=\left[\sum_{i=1}^{k}\left[\left(g_{i}-\hat{g}_{B}\right) \cdot \delta n_{i}\right] / \hat{g}_{B}+\left[\left(\hat{g}_{A} / \hat{g}_{B}\right)-1\right] H_{A}\right.$

As they take into account the observed gravity values along the leveling routes, Eqs. (1) and (3) are considered rigorous formulae for determining the $O C$.

For the sake of comparison, an approximate formula will also be considered. Such method is based on the normal potential of the reference ellipsoid [2], [8]. Particularly, taking WGS-84 as a reference ellipsoid, for a leveling line $\mathrm{AB}$, one obtains

$N O C_{A B} \approx-1.542 \times 10^{-6} H_{m} \cdot \sin 2 \varphi_{m} . \Delta \varphi_{A B}$,

where

$N O C_{A B}$ the normal orthometric correction,

$\varphi_{m}$ the mean latitude of the leveling link $\mathrm{AB}$,

$H_{m}$ the mean elevation of the leveling line,

$\Delta \varphi_{A B}=\left(\varphi_{B}-\varphi_{A}\right)$, in arc-minutes.

While the above approximate formula takes into account the general systematic features such as the mean elevation and the north-south extent of the 
leveling line, it does not consider the random effect of surface gravity variation along the leveling route.

\section{DATA}

It is worth mentioning that the purpose of the current investigation is to study the ability of using harmonic models-derived gravity to fully or partially determine the $O C$ for leveling links in Egypt; which are assumed to be spirit leveled. In particular, the investigated data are two series of adjacent stations (two lines) with known latitude, longitude, elevation and observed surface gravity data. While the first link lies in the Western Desert, the second one runs along the Nile Valley. Therefore, the first supposed route exhibits relatively rough terrain, whereas the second passes through a relatively smooth topography. Figure (2) illustrates the geographical location of both routs, which were selected for the current study. In addition, Table (1) summarizes the main features of these lines.

In fact, the available elevations under study are either trigonometrically levelled or interpolated from topographic maps. As far as the purpose is not to find the $O C$ s along an actual leveling net, this data could be considered informative for the current work. Also, an insight into Eqs. (1) and (3) implies that the precisions of both the leveled height differences and the $\mathrm{OHs}$ of the end benchmarks do not significantly affect the magnitude of the computed $O C$ itself. Such investigation strategy was decided on, since the levelling and gravity observations of the Egyptian first-order levelling networks were not available for the current study.

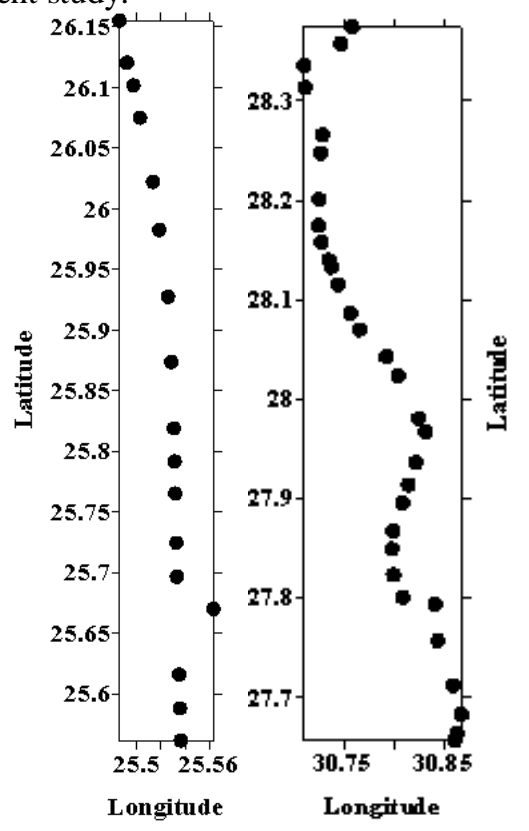

Figure (2): Post maps for the test lines (I) (left) and (II) (right)
Table (1): Summary for the two supposed leveling links

\begin{tabular}{|c|c|c|c|c|c|}
\hline$\underset{\mathbf{k}}{\operatorname{Lin}}$ & $\begin{array}{c}\text { No. } \\
\text { of } \\
\text { poin } \\
\text { ts }\end{array}$ & $\begin{array}{c}\text { Avera } \\
\text { ge } \\
\text { spacin } \\
\text { g } \\
\text { betwee } \\
\text { n } \\
\text { points } \\
\text { (km) }\end{array}$ & $\begin{array}{c}\begin{array}{c}\text { Rout } \\
\text { e } \\
\text { lengt } \\
\text { h }\end{array} \\
(\mathrm{km})\end{array}$ & $\begin{array}{c}\text { Mean } \\
\text { Elevati } \\
\text { on } \\
\text { (m) }\end{array}$ & $\begin{array}{c}\text { Elevatio } \\
\text { n } \\
\text { differen } \\
\text { ce } \\
\text { (m) }\end{array}$ \\
\hline$I$ & 17 & 4.14 & $\begin{array}{c}66.3 \\
1\end{array}$ & 352.868 & -86.940 \\
\hline II & 31 & 2.86 & $\begin{array}{c}85.7 \\
3\end{array}$ & 42.633 & -9.720 \\
\hline
\end{tabular}

\section{METHODOLOGY}

Given the geodetic latitude, longitude and elevation of an end or intermediate benchmark, the relevant geopotential model-derived surface gravity anomaly can be computed as follows [14]

$$
\begin{array}{ll} 
& \Delta g_{P M}=\left(k M / r^{2}\right) \stackrel{N \max }{\sum}(n-1)(a / r)^{n}{\stackrel{n}{\Sigma}\left(\bar{C}_{n m}^{*} \cos m \lambda\right.}_{m=0} \\
& \left.\bar{S}_{n m} \sin m \lambda\right) P_{n m}^{-}(\sin \theta),
\end{array}
$$

with

$N_{\max } \quad$ the maximum degree of the geopotential model,

$k M$ the geocentric gravitational constant,

$r$ the geocentric radius,

$a$ the equatorial radius,

$\theta$ the geocentric latitude,

$\lambda$ the geodetic longitude,

$C_{n m}^{*} \quad \& S_{n m} \quad$ the fully normalized spherical harmonic

of

coefficients of degree $\mathrm{n}$ and order $\mathrm{m}$, reduced for the even zonal harmonics

the WGS-84 reference ellipsoid,

$\bar{P}_{n m}(\sin \theta)$

the fully normalized associated

Legendre

function of degree $n$ and order $m$.

Also, the $W G S-84$ normal gravity, relevant to that benchmark, can be computed as follows

$\gamma=\left(a \gamma_{e} \cos ^{2} \varphi+b \gamma_{p} \sin ^{2} \varphi\right) / \sqrt{ }\left(a^{2} \cos ^{2} \varphi+b^{2} \sin ^{2} \varphi\right)$,

(6)

where 

$\gamma_{e} \& \gamma_{p}$
the WGS-84 normal gravity at the equator and pole, respectively, WGS-84 ellipsoid,
$\varphi \quad$ the geodetic latitude of the benchmark, relative to WGS-84.
$a \& b \quad$ the semi-major and semi-minor axis of the

And the corresponding telluroid normal gravity, $\gamma^{\prime}$, can be computed as follows

$\gamma^{\prime}=\gamma\left[1-2 / a\left(1+f+m-2 f \sin ^{2} \varphi\right) H+\left(3 / a^{2}\right)\right.$

$\left.H^{2}\right]$

where $\mathrm{H}$ is the elevation; and $\mathrm{f}$ and $\mathrm{m}$ are the geometric flattening and geodetic parameter $\left(m=\omega^{2} a^{2} b / k M\right)$ of the $W G S-84$ ellipsoid, respectively.

Finally, the geopotential model-derived surface gravity for the benchmark is computed as follows

$\begin{array}{lllll}g_{P M} & = & \gamma^{\prime} & + & \Delta g_{P M}\end{array}$ (8)

In the current work, three harmonic models were used to derive surface gravity values at leveling route benchmarks, as described above. These models are EGM2008, EIGEN-CG01C and PGM2000A [6], [10], [11] and [9]. They have maximal resolutions of 2190,360 ad 360 degrees, respectively.

For both links in Table (1), two sets of $O C$ s were computed according to the two rigorous formulae, Eqs. (1) and (3). The two sets computed by Eqs. (1) and (3) utilized the following separate categories of gravity information:

- observed gravity along all leveling sections,

- observed gravity and gravity derived from geopotential models in a staggered manner, (i.e. partially replacing the observed gravity values, see Figure (3)),

- gravity values derived from geopotential models along all leveling sections (i.e. fully replacing the observed gravity values).

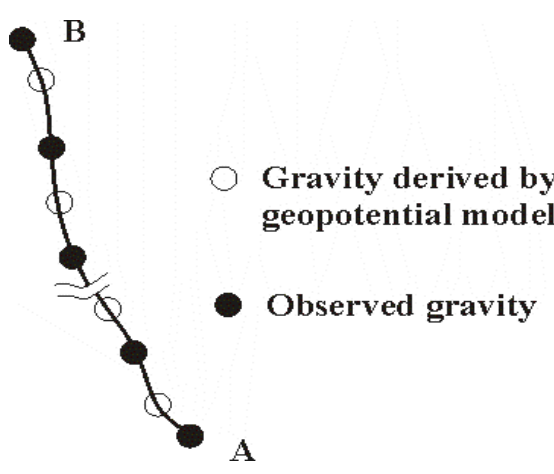

Figure ( 3): Using geopotential models to densify surface gravity values

The purpose of computing the second category is to investigate the ability of harmonic models to densify gravity values along leveling routes. Whereas the third category should check the ability of using geopotential models to replace observed gravity.

Moreover, for each link, an approximate value for the $O C$ was assessed according to Eq. (4). Tables (2) and (3) summarize all computed values for the $O C$.

\section{RESULTS}

From Tables (2) and (3), it is clear that in general the two rigorous formulae (Eqs. (1) \& (3)) give almost the same values for $O C$, which differ from those obtained by the approximate formula. It is not important to use Eq. (4), since its results are expected. Regarding the roles of harmonic models, the two tables show that the $O C$ s computed from the partial and full use of such models are closer to those computed from observed gravity values. In particular, the EIGEN-CG01C and PGM2000A models give the closest results, regarding Table (1).

Table (2): Comparison among the $O C \mathrm{~s}$ computed for the test line (I) (unit: $\mathrm{mm}$ )

\begin{tabular}{|c|c|c|c|c|}
\hline $\begin{array}{c}\text { Source of } \\
\text { gravity }\end{array}$ & $\begin{array}{c}\text { Harmonic } \\
\text { model }\end{array}$ & $\begin{array}{l}\text { Eq. } \\
\text { (1) }\end{array}$ & $\begin{array}{l}\text { Eq. } \\
(3)\end{array}$ & $\begin{array}{l}\text { Eq. } \\
\text { (4) }\end{array}$ \\
\hline Observed & & $\begin{array}{c}- \\
25.01 \\
2\end{array}$ & $\begin{array}{c}- \\
25.05 \\
5\end{array}$ & \multirow{7}{*}{$\begin{array}{c}- \\
15.20 \\
8\end{array}$} \\
\hline \multirow{3}{*}{$\begin{array}{c}\text { Staggered } \\
\text { (Observe } \\
d+ \\
\text { harmonic } \\
\text { models } \\
\text { derived) }\end{array}$} & EGM2008 & $\begin{array}{c}- \\
19.98 \\
7\end{array}$ & $\begin{array}{c}- \\
20.02 \\
2\end{array}$ & \\
\hline & $\begin{array}{c}E I G E N- \\
C G 01 C\end{array}$ & $\begin{array}{c}- \\
24.85 \\
9\end{array}$ & $\begin{array}{c}- \\
24.90 \\
2\end{array}$ & \\
\hline & $\begin{array}{c}P G M 2000 \\
A\end{array}$ & $\begin{array}{c}- \\
26.65 \\
7\end{array}$ & $\begin{array}{c}- \\
26.70 \\
3\end{array}$ & \\
\hline \multirow{3}{*}{$\begin{array}{c}\text { Only } \\
\text { derived } \\
\text { from } \\
\text { harmonic } \\
\text { models }\end{array}$} & EGM2008 & $\begin{array}{c}- \\
20.31 \\
7\end{array}$ & $\begin{array}{c}- \\
20.35 \\
2\end{array}$ & \\
\hline & $\begin{array}{c}E I G E N- \\
C G 01 C\end{array}$ & $\begin{array}{c}- \\
25.47 \\
6\end{array}$ & $\begin{array}{c}- \\
25.51 \\
9\end{array}$ & \\
\hline & $\begin{array}{c}P G M 2000 \\
A\end{array}$ & $\begin{array}{c}- \\
27.21 \\
0\end{array}$ & $\begin{array}{c}- \\
27.25 \\
6\end{array}$ & \\
\hline
\end{tabular}


Table (3): Comparison among the $O C \mathrm{~s}$ computed for test line (II) (unit: $\mathrm{mm}$ )

\begin{tabular}{|c|c|c|c|c|}
\hline $\begin{array}{c}\text { Source of } \\
\text { gravity }\end{array}$ & $\begin{array}{c}\text { Harmonic } \\
\text { model }\end{array}$ & Eq. (1) & $\begin{array}{l}\text { Eq. } \\
\text { (3) }\end{array}$ & $\begin{array}{l}\text { Eq. } \\
\text { (4) }\end{array}$ \\
\hline Observed & & -2.807 & $\begin{array}{c}- \\
2.811\end{array}$ & \multirow{7}{*}{$\begin{array}{c}- \\
2.347\end{array}$} \\
\hline \multirow{3}{*}{$\begin{array}{c}\text { Staggered } \\
\text { (Observed + } \\
\text { harmonic } \\
\text { models } \\
\text { derived) }\end{array}$} & $E G M 2008$ & -2.779 & $2 . \overline{783}$ & \\
\hline & $\begin{array}{l}\text { EIGEN- } \\
\text { CGO1C }\end{array}$ & -2.778 & $\begin{array}{c}- \\
2.782\end{array}$ & \\
\hline & PGM2000A & -2.804 & $\begin{array}{c}- \\
2.808\end{array}$ & \\
\hline \multirow{3}{*}{$\begin{array}{c}\text { Only } \\
\text { derived } \\
\text { from } \\
\text { harmonic } \\
\text { models }\end{array}$} & EGM2008 & -2.528 & $\begin{array}{c}- \\
2.532\end{array}$ & \\
\hline & $\begin{array}{l}\text { EIGEN- } \\
\text { CGO1C }\end{array}$ & -2.363 & $\begin{array}{c}- \\
2.366 \\
\end{array}$ & \\
\hline & $P G M 2000 A$ & -2.670 & $\begin{array}{c}- \\
2.673\end{array}$ & \\
\hline
\end{tabular}

\section{CONCLUDING REMARKS}

Based on the obtained results, it could be concluded that the geopotential harmonic models may be used as an economical tool for densifying/replacing gravity data along spirit leveling routes. This could be true, specially in regions with smooth gravity field natures. So it is recommended to apply such ideas in the treatment of precise leveling observations. In particular, it could be much more economic to observe the geodetic positions of the temporary intermediate benchmarks, using a single GPS receiver, than to perform gravity observations. Finally, based on the current study, it is recommended to investigate the application of the remove-compute-restore technique of geopotential models in the computation of $O C$.

ACKNOWLEDGMENTS The two reviewers are acknowledged for the critical review of the manuscript.

\section{REFERENCES}

[1] Allister, N.A. and Featherstone, W.E. (2001): "Estimation of Helmert orthometric heights using digital barcode leveling, observed gravity and topographic mass-density data over part of the Darling Scarp, Western Australia", Geomatics Research Autralasia, No. 75, pp: 25-52.

[2] Ebong, M.B. (1989): "Normal Gravity and Circuit Closures in The Nigerian Leveling", Survey Review, Vol. 30, No. 233, July.

[3] Featherstone, W.E. and Kuhn, M. (2006): "Height Systems and Vertical Datums: a Review in the Australian Context", Journal of Spatial Science, Vol. 51, No. 1, June, pp: 21-41.
[4] Heiskanen, W.A. and Moritz, H. (1967): "Physical Geodesy", W.H. Freeman and Company. [5] Hwang, C. and Hsiao, Y.-S. (2003): "Orthometric corrections from leveling, gravity, density and elevation data: a case study in Taiwan", Journal of Geodesy, 77, pp: 279-291.

[6]

http://earthinfo.nga.mil/GandG/wgs84/gravitymod / egm2008/first release.html.: "Earth Gravitational Model 2008 (EGM2008)".

[7] Jekeli, C. (2000): "Heights, the Geopotential and Vertical Datums", Report No. 459, Department of Civil and Environmental Engineering and Geodetic Science, The Ohio State University.

[8] Luz, R.T., de Freitas, R.S.C., Dalazoana, R., Baez, J.C. and Palmeiro, A.S. (2005): "Tests on Integrating Gravity and Leveling to Realize SIRGAS Vertical Reference System in Brazil", Proceedings of the IAG, IAPSO and IABO Joint Assembly: Dynamic Planet 2005 , Cairns, Australia, 22-26 August, pp: 646-652.

[9] Pavlis, N.K, Chinn, D.S., Lemoine, F.G. and Cox, C.M. (2000): "Geopotential Model Improvement Using POCM_4B Dynamic Ocean Topography Information: PGM2000A", Presented to Joint TOPEX/Poseidon and Jason-1 SWT Meeting Miami, FL, Nov. 15-17.

[10] Pavlis, N.K., Holmes S.A., Kenyon S.C., Factor J.K. (2008): "An Earth Gravitational Model to Degree 2160: EGM2008", Presented at the 2008 General Assembly of the European Geosciences Union, Vienna, Austria, April 13-18.

[11] Reigber, C., Schwintzer,P., Stubenvoll,R., Schmidt,R., Flechtner, F., Meyer, U., König, R., Neumayer, H., Förste, C., Barthelmes, F., Zhu, S.Y., Balmino, G., Biancale, R., Lemoine, J.-M., Meixner, H., Raimondo, J.C (2006): "A High Resolution Global Gravity Field Model Combining CHAMP and GRACE Satellite Mission and Surface Data, EIGENCG01C", Scientific Technical Report STR06/07, GFZ, Potsdam.

[12] Santos, M., Tenzer, R., Vaniček, P. (2003): "Effect of terrain on orthometric height", Canadian Geophysical Union Annual Meeting, Banff, 10-14 May.

[13] Tenzer, R, Vaniček, P., Santos, M., Featherstone, W.E., Kuhn, M. (2005): "The rigorous determination of orthometric heights", Journal of Geodesy, 79, pp: 82-92.

[14] Tscherning, C.C., Forsberg, R. and Knudsen, P. (1994): "GRAVSOFT - A System for Geodetic Gravity Field Modelling", Technical Note, $4^{\text {th }}$ ed January, Department of Geophysics, University of Copenhagen, Denmark. 